\title{
THE
}

2016

\section{The Effect of Tropical Cyclones on Climate Change Engagement}

\author{
Corey Lang \\ University of Rhode Island, clang@uri.edu \\ John David Ryder \\ University of Rhode Island
}

Follow this and additional works at: https://digitalcommons.uri.edu/enre_facpubs

The University of Rhode Island Faculty have made this article openly available.

Please let us know how Open Access to this research benefits you.

This is a pre-publication author manuscript of the final, published article.

Terms of Use

This article is made available under the terms and conditions applicable towards Open Access Policy Articles, as set forth in our Terms of Use.

\section{Citation/Publisher Attribution}

Lang, C., \& Ryder, J. D. (2016). The Effect of Tropical Cyclones on Climate Change Engagement. Climatic Change, 135(3), 625-638.

Available at: http://dx.doi.org/10.1007/s10584-015-1590-0

This Article is brought to you for free and open access by the Environmental and Natural Resource Economics at DigitalCommons@URI. It has been accepted for inclusion in Environmental and Natural Resource Economics Faculty Publications by an authorized administrator of DigitalCommons@URI. For more information, please contact digitalcommons-group@uri.edu. 


\title{
The Effect of Tropical Cyclones on Climate Change Engagement
}

\author{
Corey Lang ${ }^{\mathrm{a},{ }^{*}}$ and John David Ryder ${ }^{\mathrm{a}}$ \\ ${ }^{\text {a }}$ Department of Environmental and Natural Resource Economics, University of Rhode Island, 1 Greenhouse Rd., \\ Kingston, RI, 02881, USA. \\ * Corresponding author. E-mail address: clang@uri.edu
}

\begin{abstract}
Personal experience can influence our attitudes and actions concerning climate change. This paper examines the experience-perception link in relation to tropical cyclones using a distinctly revealed preference approach, mitigating biases of prior research in this area. Specifically, we study how people alter their internet searches related to climate change in response to tropical cyclones. Using data for the United States 2006-2012, results suggest that searches related to climate change increase with a lag in the months following an event. This finding indicates that the people are connecting tropical cyclones to the broader narrative of climate change in the aftermath of an event and there may be a window of opportunity for building public support for policy action.
\end{abstract}

Keywords: Hurricanes; Tropical cyclones; Experience-perception link; Google Trends; Climate change

\section{Acknowledgements}

Carrie Gill is thanked for excellent research assistance. Laura Bakkensen and two anonymous referees are thanked for useful comments. This paper is a contribution of the Rhode Island Agricultural Experiment Station (\#5431). 


\section{Introduction}

From 1963 to 2012, tropical cyclones (TCs) in the Atlantic Basin were directly responsible for 2,544 deaths, an average of fifty deaths each year (Rappaport 2014). In 2012, North Atlantic TCs caused 195 deaths and \$52 billion in damages (Stewart 2014). Economic damages persist following TC landfall; economic growth is estimated to decline 0.45 percentage points for US counties hit (Strobl 2011). Despite the risks of TCs, evidence of human adaptive response is mixed. High-risk countries that experience more frequent intense TCs have between 3-19 percent fewer damages compared to low-risk countries, which researchers attribute to adaptation (Hsiang and Narita 2012; Bakkensen and Mendelsohn 2015). However, the United States shows evidence of maladaptation through relatively high rates of damages and fatalities, in contrast to other OECD countries (Bakkensen and Mendelsohn 2015).

Damages caused by TCs may increase in the future for two reasons. First, losses are expected to increase as population and wealth concentration along vulnerable coastlines continues to grow (Peduzzi et al. 2012). Second, while there is uncertainty and debate, some scientists and climate models project that climate change will alter the behavior of TCs, such as increasing the frequency of intense TCs or the duration of highest intensity (Knutson et al. 2010; Villarini and Vecchi 2012; Stocker et al. 2013). ${ }^{1}$ If the frequency of intense TCs increases as some climate models project, Mendelsohn et al. (2012) estimate an increase in annual damages of US\$53 billion by 2100, controlling for changing socioeconomic factors over time.

The purpose of this paper is to understand if individuals are making a connection between TCs and climate change. This association could be an important channel for understanding attitudes and behavior. Individuals that believe they have personally experienced climate change are likely to have higher awareness of and concern for the associated risks (Weber 2006), which could have implications for disaster preparedness and climate adaptation. While attributing a single event to climate change is technically incorrect, if people engage more with climate change as a result of a weather event, it could present a window of opportunity to build political support for greenhouse gas mitigation policy.

Prior literature exploring the experience-perception link has focused primarily on the effect of temperature on individuals' beliefs in climate change. Warmer than average days induce

\footnotetext{
${ }^{1}$ We acknowledge the debate regarding projections for intensity and frequency of tropical cyclones due to climate change and refrain from taking a particular stance.
} 
more people to believe in climate change, and even donate more to an environmental charity (Li et al. 2011; Hamilton and Stampone 2013; Egan and Mullin 2012). Beyond temperature, changes in seasonal timing and experience with flooding significantly increase belief in climate change and stated willingness to save energy (Akerloff et al. 2013; Spence et al. 2011).

However, the mechanism behind the connection between weather and stated beliefs is likely driven by attribute substitution, the act of answering a relatively simple yet less relevant question (e.g. “Is today’s temperature colder or warmer than usual?”) in place of a more complex or abstract question (e.g. "How convinced are you that climate change is happening?”) (Zaval et al. 2014). Further, Druckman (2015) shows that priming individuals to consider climate instead of weather can eliminate the connection. In addition to problems with psychological bias, the vast majority of these studies that examine the experience-perception link used a stated preference methodology, relying on self-reported measures in surveys. In the context of climate change, a polarizing and contentious topic in politics, stated preference data may suffer from biases, including strategic behavior like posturing or protesting to project beliefs consistent with political allies (Podsakoff et al. 2003).

In contrast, this paper takes a distinctly revealed preference approach to explore how engagement with climate change varies following a TC. We use internet search data from Google Trends, which offers a measure of relative popularity of a search term for a given time and location. Google Trends data are being increasingly used as a measure of contemporary awareness across of wide variety of indicators (Ginsberg et al. 2009; Choi and Varian 2012). Internet searches, which typically occur privately and anonymously, reveal information about engagement with climate change that may be obscured in public channels. While Internet searches do not necessarily reveal beliefs, searches do represent preferences for engagement with ideas. This revealed preference approach allows us to better understand whether the public is making a connection between TCs and climate change, mitigating risk of survey bias (StephensDavidowitz 2013). Notably, Google Trends, as well as Twitter, data have been used to show that climate change interest increases when there are temperature and precipitation anomalies consistent with climate change and decrease when unemployment increases (Kahn and Kotchen 2011; Herrnstadt and Muehlegger 2014; Lang 2014; Kirilenko et al. 2015). Beatty et al. (2015) use a different revealed preference approach by examining bottled water sales caused by 
hurricane risk. Interestingly, they find that sales only increase following a hurricane, indicating a lack of risk mitigation.

We built a panel dataset of monthly online engagement and TC impacts for each of 202 designated market areas (DMAs; essentially, metropolitan areas) in the conterminous United States for 2006-2012. We collected Google Trends data on monthly query share for the search keyword "hurricane" and the union of keywords "climate change" and "global warming", henceforth these search terms will be denoted in italics as hurricane and climate change + global warming. We matched search interest for each DMA to location and characteristics of tropical storms and hurricanes collected from NOAA. Using panel data methods, we empirically model query share for each search term as a function of exposure to TC events and explore heterogeneity by underlying risk, coastal location, and distance from the DMA to the TC track.

The results suggest that search interest for hurricane spikes in areas that are impacted by tropical storms and hurricanes in the month of the event. In contrast, online engagement with climate change does not significantly change during the month of a TC event, but increases with a lag over the following two months. Further, areas of high TC risk show greater online engagement with climate change when hit by TCs than low-risk areas. Our results suggest a shift in online engagement from hurricanes to climate change in the months following tropical storms and hurricanes, and confirm an experience-perception link between TCs and interest in climate change.

This paper contributes to the literature that seeks to understand how personal experience of weather events can influence interest and belief in climate change. While prior literature has examined the experience-perception link primarily using temperature, but also precipitation, flooding and seasonal change, to the best of our knowledge this is the first paper to study this relationship using TCs. This is important as TCs are far more damaging than small temperature changes.

Zaval et al. (2014) make a compelling case that empirical evidence of changes in climate change beliefs resulting from temperature fluctuations are meaningless because psychological bias is the driving factor, and Druckman (2015) shows this bias can be broken by priming individuals to consider weather patterns. We have responded by using revealed preference data that represent intentional actions not prodded by a phone call. We argue that self-directed searches are inherently different than responding to prompted survey questions. And, while the 
media and political conversation may well include linkages of TCs to climate change, online engagement can only be self-motivated. Further, our results that the experience-perception response is delayed suggest that our findings are not due to attribute substitution; unlike the salience of today's temperature, a temporal lag renders the TC a much less available substitute. Instead, we argue that our findings show a self-directed exploration of a complex topic.

\section{Data}

\subsection{Google search activity}

To examine the extent to which the public seeks information about climate change during and following a TC, we collected a panel dataset of monthly Google search activity for all 202 designated market areas (DMAs) in the conterminous US using Google Trends. ${ }^{2}$ DMAs are the smallest geographic area at which Google Trends releases data and consist of several contiguous counties, which can be thought of as cities and their surrounding areas. Google Trends provides a time series index of search activity, which we'll refer to as Google Search Index (GSI). GSI is reported on a 0-100 scale with 100 being the maximum search query share over the specified time frame, and all other nonzero values are that percentage of this maximum. ${ }^{3}$ For example, for the aggregate US between January 2006 and December 2012, the maximum GSI (GSI=100) for the search term hurricane occurred in August 2011, indicating that the largest share of queries for hurricane in relation to total searches occurred during this month. That Hurricane Irene also occurred in August 2011 is suggestive, but not conclusive, of a link between hurricane GSI and a TC event. In comparison, GSI for hurricane was 86 in October 2012 during Hurricane Sandy, meaning that query share for hurricane was only 86 percent of the query share that occurred in the month of Hurricane Irene. This does not mean that search volume was 14 percentage points higher in August 2011 than October 2012 because the volume of other searches may have changed over that time. If the number of queries did not reach an undisclosed threshold, GSI equals zero. At the DMA level, GSI represents a query share for each DMA in relation to that DMA's maximum search volume. With GSI as our key dependent variable, as discussed

\footnotetext{
${ }^{2}$ We encourage interested readers to visit Google Trends at www.google.com/trends to explore the data visualization platform.

${ }^{3}$ While both query share and absolute search volume are meaningful, we would expect results to be similar for each given that absolute search volume increases over time. Unfortunately, absolute search volume is unavailable. Query share, however, provides additional benefits of controlling for relative importance and prioritization of searches for each geographic region.
} 
thoroughly in the next section, we interpret our model coefficients as a percentage point change in query share.

We use Google Trends data from January 2006 through December 2012. Google Trends data are available from January 2004, but we excluded 2004-2005 as two-thirds of DMAs recorded a GSI of zero, indicating the minimum threshold not being reached. Because these are artificial zeros (search volume was actually changing, just at levels below the threshold), including these zeroes will attenuate our estimates of the impact of hurricanes on GSI. To further prevent attenuation bias, we follow Lang (2014) and drop leading zeroes up until the point at which eight out of ten of the subsequent observations are non-zero; essentially we wait to include a DMA's time series until that DMA consistently exceeds the search minimum. Results are similar for alternative thresholds. TC data from NOAA were only available through the end of 2012, so this was the end point of our study. The majority of DMAs contained monthly data; some that included large cities such as New York or Chicago contained weekly data. Weekly data were converted to an average monthly GSI for consistency.

We downloaded data for climate change + global warming, which is the union of the two search terms “climate change” and "global warming”, for each DMA separately, which is appropriate for the panel data estimators. Each time series ranges 0-100. Due to low search volume in rural areas and Google’s disclosure policy, climate change + global warming data are available for only 154 DMAs, though these DMAs collectively represent 95 percent of the US population (Table 1). Additionally, we gathered data for the search term hurricane, which serves to benchmark how people use Internet resources in the context of TCs. While language referring to "tropical cyclones" is scientifically more accurate when describing both tropical storms and hurricanes, "hurricane" is a more colloquial term than "tropical cyclone” in the US. ${ }^{4}$ Data on hurricane query share covers 182 DMAs, representing 99 percent of the US population (Table 1). The unit of observation is DMA-month-year, which amounts to a maximum of 12,936 (=154 DMAs*12 months*7 years) observations for climate change + global warming GSI and 15,288 observations for hurricane GSI. However, the actual number of observations drops to 10,372 and 11,705, respectively, when leading zeroes are removed.

\subsection{Tropical cyclone data}

\footnotetext{
4 “Tropical cyclone” does not register a non-zero GSI over our sample timespan when compared to "hurricane”.
} 
We matched Google search data with TC data for the North Atlantic basin 2006-2012. We use HURDAT data from NOAA National Hurricane Center. Data contain TC eye coordinates and 36-knot wind radius buffers at six-hour intervals over the lifespan of each TC. We merged individual TC data points by storm identification to create a continuous track. To appropriately account for the width and zone of influence of each TC, we used wind radii measurements to create a buffer zone around each TC path. By overlaying the buffered TC tracks onto the DMA shapefile in ArcGIS, we calculated the number of times each DMA was hit by a TC in each month, with hit defined as intersection of wind-buffered track and DMA polygon. Table 2 presents classifications of the 47 TCs that hit the conterminous US. Ten of the TCs do not make landfall, but are included because their buffered track does touch land. We categorize each TC by the maximum category it is rated over its entire course as an approximate proxy for the publicity that the storm generated. Eight of 47 TCs in our sample are rated Category 3 or 4 at some point in their lifetimes. These categorizations are used to restrict the dataset in some empirical specifications but they do not appear explicitly in our models. In specifications where we only consider major TCs (category 3 and stronger), our method of categorization would allow weaker storms into the sample, resulting in conservative estimates of the effects of major TCs on engagement.

Typically, the hurricane impact literature only accounts for landfall characteristics (Mendelsohn et al. 2012, Bakkensen 2013), but this dataset allows us to characterize each TC's zone of influence. While the recorded track of each TC has negligible width, impacts of the TC are often felt at a larger scale (Howe et al. 2014). Buffering the TC track according to wind radii allows us to more accurately model the area impacted by the TC. In addition, this method captures the impacted coastal areas of Atlantic TCs that never actually make landfall, which otherwise would be filtered from the dataset. Similarly, Beatty et al. (2015) use a 125-mile radius buffer around forecasted landfall locations to capture the effect of TCs on bottled water sales in potentially impacted communities, and Strobl (2011) and Hsiang (2010) both use statistical methods to estimate the radius of maximum winds.

Figure 1 Panel a shows the TC tracks in our sample and the frequency with which DMAs were hit by the wind-radii buffered path. During 2006-2012, 47 tropical storms and hurricanes hit 151 DMAs, representing 74 percent of the US population (Table 1). 


\section{Empirical strategy}

We develop several regression models to quantify the experience-perception link with respect to TCs and online engagement; these are presented in Equations 1-3. Our response variable, $G I_{i t}$, is Google search index for hurricane and for climate change + global warming. Importantly, we allow for heterogeneous effects along many dimensions, including spatially, temporally, by underlying risk, and by whether the DMA was hit. We interpret our results for all models as causal because our modeling strategy controls for temporally and spatially invariant determinants of online engagement and, due to the randomness of their arrival, TCs are unlikely to be correlated with other determinants of search behavior.

\subsection{Heterogeneity by underlying risk}

First, we explore heterogeneity in effects by underlying risk of TCs, thinking that repeated exposure may dampen or heighten certain impacts. This model also allows for engagement to change both for DMAs hit as well as DMAs that are missed, our intuition being that even people not directly affected may connect TC events to climate change. Equation 1 explores the effect of TCs on GSI and how this relationship varies by underlying TC risk and by whether the DMA was hit:

$$
\text { GSI }_{i t}=\beta_{1} \text { Hits }_{i t} \cdot \text { HighRisk }_{i}+\beta_{2} \text { Hits }_{i t} \cdot \text { LowRisk }_{i}+\beta_{3} \text { HighRiskMiss }_{i t}+\theta_{i}+\gamma_{t}+\varepsilon_{i t}
$$

where Hits it $_{\text {is }}$ the number of times DMA $i$ is hit by a TC in month $t$ and HighRisk $i$ and LowRisk $_{i}$ are defined as in Figure 1. Using annual TC data from 1970-2012, we defined a DMA to be high-risk if that DMA was hit by an average of three or more TCs annually and low-risk otherwise; Figure 1 Panel b illustrates our distinctions of high vs. low risk. HighRiskMiss ${ }_{i t}$ is binary and equals 1 if DMA $i$ is high risk and a TC occurs in month $t$ but does not hit $i$. The omitted group is the LowRiskMiss set of DMAs and, thus, coefficients are interpreted as changes in GSI relative to low-risk DMAs that are not hit by a TC in a month in which a TC exists somewhere. Equation 1 also includes DMA fixed effects, $\theta_{i}$, which capture any time invariant determinants of GSI that may be correlated with hurricane frequency, but not causally related. 
Lastly, year-month fixed effects, $\gamma_{t}$, are included to account for nationwide events that may have influenced query share and that are part of the larger social context during this timeframe (e.g. the release of An Inconvenient Truth). During months with TC events, the omitted group identifies the baseline response, which we assume to be negligible. To the extent that there is an impact of TC events in low-risk, not hit areas, our estimates will be lower bounds of the total effect. However, this is a necessary modeling choice to remove endogeneity concerns. The coefficients of interest, $\beta_{1}$ through $\beta_{3}$, estimate a deviation from the month-specific national average and DMA-specific average query share.

\subsection{Heterogeneity by coastal and inland location}

Next, we allow for different effects for coastal and inland DMAs, given that TC damages are much greater on the coast. Equation 2 explores how the relationship between TCs and GSI vary by coastal/inland location and by whether the DMA was hit:

$$
\text { GSI }_{i t}=\beta_{1} \text { Hits }_{i t} \cdot \text { Coast }_{i}+\beta_{2} \text { Hits }_{i t} \cdot \text { Inland }_{i}+\beta_{3} \text { CoastMiss }_{i t}+\theta_{i}+\gamma_{t}+\varepsilon_{i t}
$$

where Coast $_{i}$ and Inland $_{i}$ are defined as in Figure 1 Panel b, CoastMiss $i t$ is binary and equals 1 if DMA $i$ is coastal and a TC occurs in month $t$ but does not hit $i$. Coefficients are interpreted as changes in GSI relative to inland DMAs that are not hit by a TC in a month in which a TC exists somewhere. Similar to Equation 1, this model includes DMA fixed effects, $\theta_{i}$, and yearmonth fixed effects, $\gamma_{t}$.

\subsection{Heterogeneity by distance to TC}

Lastly, we model how distance from the path of the TC affects engagement. Equation 3 explores how GSI varies by a quadratic function of distance from a TC track

$$
G S I_{i t}=\beta_{1} \text { Distance }_{i t}+\beta_{2} \text { Distance }_{i t}^{2}+\theta_{i}+\gamma_{t}+\varepsilon_{i t}
$$

where Distance $_{i t}$ is the distance from DMA i's centroid to the nearest wind-radii buffered TC track in month $t, \theta_{i}$ are DMA fixed effects, and $\gamma_{t}$ are year-month fixed effects. We model the relationship between GSI and distance as a quadratic function to allow for non-linearity. For 
simplicity, we have written each model using $\beta, \theta, \gamma$, and $\varepsilon$, but to be precise these parameters are allowed to differ across models.

\subsection{Temporal heterogeneity}

To build intuition of our modeling strategy, we have written each model using only concurrent impacts of TCs on GSI. However, our full models allow for lagged effects. Specifically, we modify Equations 1-3 to include TC activity in the prior month (t-1) and two months prior ( $t-2)$. For example, Equation 1 becomes

$$
\begin{aligned}
\text { GSI }_{\text {it }}=\beta_{1} \text { Hits }_{i t} & \cdot \text { HighRisk }_{i}+\beta_{2} \text { Hits }_{i t} \cdot \text { LowRisk }_{i}+\beta_{3} \text { HighRiskMiss }_{i t}+\beta_{4} \text { Hits }_{\text {it }-1} \cdot \text { HighRisk }_{i} \\
& +\beta_{5} \text { Hits }_{i t-1} \cdot \text { LowRisk }_{i}+\beta_{6} \text { HighRiskMiss }_{i t-1}+\beta_{7} \text { Hits }_{i t-2} \cdot \text { HighRisk }_{i} \\
& +\beta_{8} \text { Hits }_{i t-2} \cdot \text { LowRisk }_{i}+\beta_{9} \text { HighRiskMiss }_{i t-2}+\theta_{i}+\gamma_{t}+\varepsilon_{i t}
\end{aligned}
$$

Equations 2 and 3 are similarly modified. A clarifying example illustrates the temporal component: consider GSI for a particular search term in August 2010. Our model includes separately TCs that occur in August (the month concurrent with GSI), July (GSI lags TC activity by one month), and June (GSI lags TC activity by two months).

\section{Results}

4.1 The effect of TCs on hurricane GSI

We first explored the effect of TCs on search activity for hurricane. Table 3 presents the results. In contrast to high-risk DMAs, which do not significantly increase searches related to hurricanes when they are hit, low-risk DMAs increase query share by 10.54 percentage points $(p=0.00)$ more than low-risk DMAs that are not hit. This increase in engagement grows to 16.74 percentage points $(p=0.00)$ for low-risk DMAs hit by a major TC (Category 3 or stronger). Hurricane query share declines in the months following a TC for all hit DMAs. The difference between high-risk and low-risk DMAs in search behavior is rather intuitive and supports the idea that individuals who are frequently hit are more knowledgeable about the associated risk.

Coastal and inland DMAs that are hit increase hurricane query share by $7.51(p=0.00)$ and $6.52(p=0.00)$ percentage points more than missed inland DMAs, respectively. Major TCs have a more pronounced effect; coastal and inland DMAs increase query share by 18.09 
$(p=0.00)$ and $13.58(p=0.00)$ percentage points more than missed inland DMAs, respectively. These effects decline in months following a TC.

Overall, these results corroborate and extend prior research on hurricane-related information seeking (Sherman-Morris et al. 2011), validate the data and research design, and establish a basic experience-perception link. However, this paper seeks to go further and understand how TC experience leads to connections with the larger narrative of climate change.

\subsection{The effect of TCs on GSI for climate change + global warming}

Table 4 presents results from estimates of TCs on search activity for climate change + global warming. In contrast to hurricane-related search activity, our results suggest that there is little to no change in online engagement related to climate change in the same month as a TC event, but engagement does increase with a lag over the two-month period following the TC event. High-risk DMAs that are hit show a lagged increase in engagement of $1.56(p=0.07)$ and $3.89(p=0.01)$ percentage points in the first and second months following the TC, respectively. Low-risk DMAs that are hit show an increase with a two-month lag ( $\beta=1.44, p=0.07)$. High-risk DMAs that are not hit show an increase during the month concurrent with the TC event $(\beta=1.91$, $p=0.06$ ). For major TCs, the results also suggest increased online engagement regarding climate change; however, these results are significant only for low-risk DMAs two months after they are hit.

The results are cloudier for the models comparing coastal and inland DMAs, but suggest a similar pattern of increasing climate change engagement over time. Results show an increase in online engagement with a one-month lag in coastal DMAs that are hit $(\beta=1.28, p=0.08)$ and with a two-month lag for inland DMAs that are hit $(\beta=2.45, p=0.01)$. Coastal DMAs that are missed do not show a significant change in online engagement, but the results are suggestive of an increase with a two-month lag. For major TCs, the results support the idea of increasing online engagement over the two months following the TC event. Inland DMAs that are hit show increases in query share in both the first $(\beta=2.08, p=0.05)$ and second months $(\beta=3.32, p=0.00)$ following a TC. Coastal DMAs that are missed also show increases both in the concurrent month $(\beta=2.28, p=0.09)$ and with a two-month lag $(\beta=3.66, p=0.02)$.

Examining Tables 3 and 4, two key patterns emerge. First, areas that are hit, whether high- or low-risk or coastal or inland, show increases in climate change-related search activity as 
time passes. One possible explanation is that in the month of the TC event, all energy is focused on the immediate concern, and thus hurricane GSI increases. But in the months following an event, when immediate concerns abate, engagement shifts towards the larger trend of climate change. Second, high-risk and coastal areas show some evidence of climate change engagement in the month of the TC event, but little evidence of increases in hurricane GSI. One interpretation is that people with TC experience are less concerned about TCs affecting other parts of the country, but their experience primes them to consider climate change.

With respect to distance from a TC track, we find that climate change engagement increases as distance decreases (Table 5). Consistent with findings in Table 4, there is no change in engagement in the month of the TC event, but patterns emerge in the months following the event. In the first month following a TC event, query share increases $2.12(p=0.01)$ percentage points for every thousand miles closer a DMA is to the TC's zone of influence. This rate of increase gets smaller as distance between the DMA and TC grows. The effect of proximity is similar in the second month.

\subsection{Falsification tests}

We conduct placebo tests to increase confidence that our results are not spurious. We model climate change + global warming GSI as a function of TC events in the following month (i.e. a one-month lead), which should have no correlation after controlling for year-month and DMA fixed effects. Table 6 presents results of six placebo tests by heterogeneity in underlying risk (panels a and d), DMA location (panels b and e), and distance to the TC track (panels c and f) for the full model (panels a, b, and c) and major TC events only (panels d, e, and f). All results are statistically indistinguishable from zero, as expected. These results suggest there is no unobservable trend in GSI driving our main results, thereby bolstering our interpretation of results in Tables 4 and 5.

\section{Discussion}

The results point to an informative shift in online focus. While hurricane-related online engagement increases during the month of the TC and subsequently decreases, search interest

related to climate change shows no significant change during month of the hit but increases with a lag over the two months following the TC event. This shift is perfectly intuitive. During a TC 
event, people are rightfully focused on the event. However, in the aftermath when they have time to think, talk, and analyze, they begin to connect the event to the larger narrative of climate change. There are several possible mechanisms through which this connection could be made including introspection, social networks, media, and political conversations. Unfortunately, our research cannot distinguish between these possible mechanisms (an area of future exploration), but we can say that individuals seek information for themselves following a TC. We argue that this self-directed engagement, regardless of mechanism, is evident of individuals making a link between TCs and climate change. Further, the delay in appearance of the experience-perception link suggests that this finding is not due to attribute substitution, unlike many prior results in this literature, but instead reflects a deeper, more deliberate connection between events and trends. The findings of this paper have important implications for public risk perception and optimal timing of climate change outreach or policy action. Specifically, major weather events associated with climate change may provide a window of opportunity for building support for greenhouse gas mitigation efforts or public adaptation policies.

While this paper demonstrates a causal link between TCs and information seeking related to climate change, we cannot know whether the public is gathering accurate information or how they use that information. Google's search algorithm effectively reduces the choice set of websites to click on by predicting which websites the searcher is mostly likely to click on and displaying those most prominently on the first pages of search results. A limitation of our research is that we cannot measure which websites individuals visit following a search or what information they view and retain. Instead our research looks only at engagement and initiation, which we perceive as crucial steps in identifying the existence of an experience-perception link. Measuring learning and learning outcomes should indeed be a future topic for research. Information seeking could lead to measurable outcomes, as information exposure can change voting behavior (DellaVigna and Kaplan 2007) and the decision to buy carbon offsets (Jacobsen 2011). Future research could examine if self-directed internet learning has a similar effect in the context of adaptation and disaster preparedness. 


\section{References}

1. Akerlof K, Maibach EW, Fitzgerald D, Cedeno AY, Neuman A (2013) Do people 'personally experience' global warming, and if so how, and does it matter? Global Environmental Change 23:81-91.

2. Bakkensen LA, Mendelsohn, R (2015) Risk and Adaptation: Evidence from Global Hurricane Damages and Fatalities. University of Arizona Working Paper.

3. Beatty TKM, Shimshack JP, Volpe RJ (2015) Disaster preparedness and disaster response: Evidence from bottled water sales before and after tropical cyclones. University of Virginia working paper.

4. Choi H, Varian H (2012) Predicting the Present with Google Trends. Economic Record 88:2-9.

5. DellaVigna S, Kaplan E (2007) The Fox News Effect: Media Bias and Voting. The Quarterly Journal of Economics 122:1187-1234.

6. Druckman JN (2015) Eliminating the local warming effect. Nature Climate Change 5:176177.

7. Egan PJ, Mullin M (2012) Turning Personal Experience into Political Attitudes: The Effect of Local Weather on Americans’ Perceptions about Global Warming. The Journal of Politics 74:796-809.

8. Ginsberg J, Mohebbi MH, Patel RS, Brammer L, Smolinski MS, Brilliant L (2009) Detecting influenza epidemics using search engine query data. Nature 457:1012-1014.

9. Hamilton LC, Stampone MD (2013) Blowin' in the Wind: Short-Term Weather and Belief in Anthropogenic Climate Change. Weather, Climate, and Society 5:112-119.

10. Herrnstadt E, Muehlegger E (2014) Weather, salience of climate change and congressional voting. Journal of Environmental Economics and Management 68:435-448.

11. Howe PD, Boudet H, Leiserowitz A, Maibach EW (2014) Mapping the shadow of experience of extreme weather events. Climatic Change 127:381-389.

12. Hsiang SM, Narita D (2012) Adaptation to cyclone risk: Evidence from the global crosssection. Climate Change Economics 3(02).

13. Hsiang SM (2010) Temperatures and cyclones strongly associated with economic production in the Caribbean and Central America. Proceedings of the National Academy of Sciences 107(35):15367-15372.

14. Jacobsen GD (2011) The Al Gore Effect: An Inconvenient Truth and Voluntary Carbon Offsets. Journal of Environmental Economics and Management 61:67-78.

15. Kahn ME, Kotchen MJ (2011) Business cycle effects on concern about climate change: The chilling effect of recession. Climate Change Economics 2:257-73.

16. Kirilenko AP, Molodtsova T, Stepchenkova SO (2015). People as sensors: Mass media and local temperature influence climate change discussion on Twitter. Global Environmental Change 30:92-100. doi:10.1016/j.gloenvcha.2014.11.003

17. Knutson TR et al (2010) Tropical cyclones and climate change. Nature Geoscience 3:157163. 
18. Lang C (2014) Do Weather Fluctuations Cause People to Seek Information about Climate Change? Climatic Change 125:291-303.

19. Li Y, Johnson EJ, Zaval L (2011) Local Warming: Daily Temperature Change Influences Belief in Global Warming. Psychological Science 22:454-459.

20. Mendelsohn R, Emanuel K, Chonabayashi S, Bakkensen L (2012) The impact of climate change on global tropical cyclone damage. Nature Climate Change 2:205-209.

21. Peduzzi P et al (2012) Global trends in tropical cyclone risk. Nature Climate Change 2:289294.

22. Podsakoff PM, MacKenzie SB, Lee JY, Podsakoff NP (2003) Common method biases in behavioral research: A critical review of the literature and recommended remedies. Journal of Applied Psychology 88:879-903.

23. Rappaport EN (2014) Fatalities in the United States from Atlantic Tropical Cyclones: New Data and Interpretation. Bulletin of the American Meteorological Society 95:341-346.

24. Sherman-Morris K, Senkbeil J, Carver R (2011) Who’s Googling What? What Internet Searches Reveal about Hurricane Information Seeking. Bulletin of the American Meteorological Society 92:975-85.

25. Spence A, Poortinga W, Butler C, Pidgeon NF (2011) Perceptions of climate change and willingness to save energy related to flood experience. Nature Climate Change 1:46-49.

26. Stephens-Davidowitz S (2013) The effects of racial animus on a black presidential candidate: using Google search data to find what surveys miss. Harvard University Working Paper.

27. Stewart S (2014) National Hurricane Center Annual Summary. at $<$ https://gdx.ncrnet.us/ncrgdx/share/713AEE22-CA85-423B-BCFF571A6C90BD9B/data/tcr/summary_atlc_2012.pdf>

28. Stocker TF et al (2013) Climate change 2013: The physical science basis. Intergovernmental Panel on Climate Change, Working Group I Contribution to the IPCC Fifth Assessment Report (AR5) (Cambridge Univ Press, New York). at <http://www.climatechange2013.org/images/report/WG1AR5_Frontmatter_FINAL.pdf>

29. Strobl E (2011) The economic growth impact of hurricanes: evidence from US coastal counties. Review of Economics and Statistics 93:575-589.

30. Villarini G, Vecchi GA (2012) Twenty-first-century projections of North Atlantic tropical storms from CMIP5 models. Nature Climate Change 2:604-607.

31. Weber EU (2006) Experience-Based and Description-Based Perceptions of Long-Term Risk: Why Global Warming does not Scare us (Yet). Climatic Change 77:103-120.

32. Zaval L, Keenan EA, Johnson EJ, Weber EU (2014) How warm days increase belief in global warming. Nature Climate Change 4:143-147. 


\section{Figure 1}

Sample data and key variables.
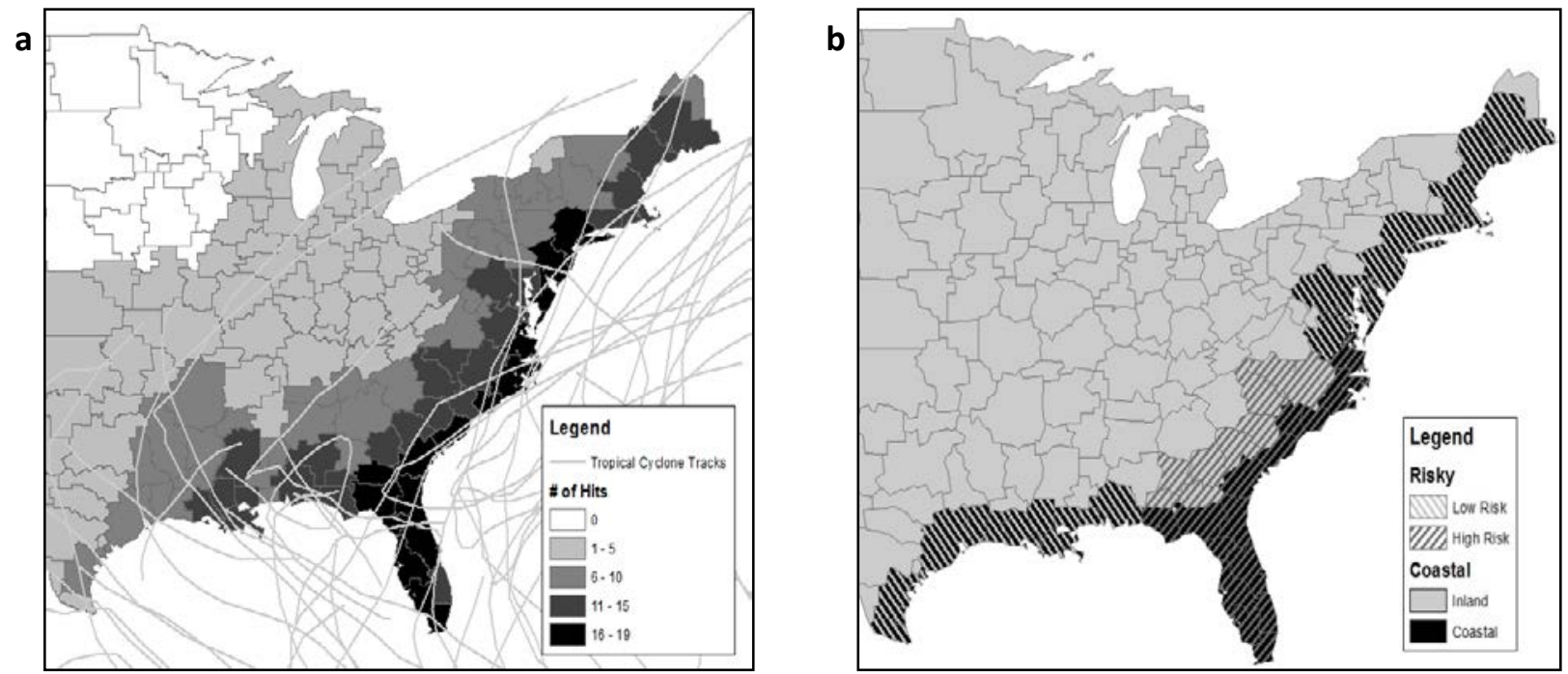

Notes: a displays tracks for tropical cyclones 2006-2012 in our sample. Each DMA is color coded based on the number of times it falls within the wind buffer of a hurricane track. $\mathbf{b}$ displays Coastal and Inland DMAs in solid colors, and high-risk and low-risk DMAs hash marked. High-risk areas are defined as those hit on average three times per year from 1970-2012. Coastal areas are those located on the Gulf or Atlantic Coast. See Tables 1 and 2 for summary statistics. 
Table 1

Summary statistics.

\begin{tabular}{lcc}
\hline & \multicolumn{2}{c}{ Google Search Index } \\
& Hurricane & $\begin{array}{c}\text { Global Warming + } \\
\text { Climate Change }\end{array}$ \\
\hline Observations & 11,705 & 10,372 \\
Mean observations per DMA & 75.2 & 73.7 \\
Number of sample DMAs & 182 & 154 \\
Proportion of US population represented in sample DMAs & 0.99 & 0.95 \\
Mean Google Search Index (GSI) & 5.1 & 31.2 \\
Mean number of Tropical Cyclone (TC) hits per month & 0.05 & 0.05 \\
Mean number of TC hits per DMA 2006-2012 & 3.33 & 3.15 \\
Proportion of sample months with TC hit & 0.29 & 0.29 \\
\hline & \multicolumn{2}{c}{ Tropical Cyclones } \\
Maximum sustained wind speed (knots) & Mean (St. Dev.) & Min - Max \\
Category & 68.1 (21.5) & 17.1 - 99.3 \\
\hline
\end{tabular}

Notes: Sample includes designated market areas (DMAs) in conterminous United States 2006-2012 with nonzero GSI in eight out of ten consecutive months at some point during the timespan. Topical cyclone statistics are for wind-buffered TCs that hit the conterminous United States 2006-2012 $(N=47)$. 
Table 2

Sample tropical cyclone summary statistics, 2006-2012.

\begin{tabular}{lccc}
\hline National Hurricane Center classification & Total & Made landfall & Did not make landfall \\
\hline Tropical Storm & 28 & 27 & 1 \\
Hurricane Category 1 & 7 & 4 & 3 \\
Hurricane Category 2 & 4 & 2 & 2 \\
Hurricane Category 3 & 2 & 2 & 0 \\
Hurricane Category 4 & 6 & 2 & 4 \\
Hurricane Category 5 & 0 & 0 & 0 \\
\hline
\end{tabular}




\section{Table 3}

The effect of Tropical Cyclones on hurricane Internet search interest

\begin{tabular}{|c|c|c|c|c|c|}
\hline \multirow[b]{3}{*}{ Hits•HighRisk } & (a) & (b) & \multirow[b]{3}{*}{ Hits $\bullet$ Coastal } & \multirow{3}{*}{$\begin{array}{c}\text { (c) } \\
\text { Full model } \\
\end{array}$} & \multirow{3}{*}{$\begin{array}{c}\text { (d) } \\
\text { Major TCs only } \\
\end{array}$} \\
\hline & Full model & Major TCs only & & & \\
\hline & & & & & \\
\hline Current month & $1.068(1.537)$ & $11.374(7.577)$ & Current month & $7.507(1.600)^{* * *}$ & $18.087(3.744)^{* * *}$ \\
\hline 1 month lag & $-0.094(0.317)$ & $-0.602(1.660)$ & 1 month lag & $-0.263(0.349)$ & $-0.639(1.093)$ \\
\hline 2 months lag & $-0.530(0.390)$ & $0.639(0.308)^{* *}$ & 2 months lag & $-0.740(0.402)^{*}$ & $-0.083(0.326)$ \\
\hline \multicolumn{3}{|l|}{ Hits $\bullet$ LowRisk } & \multicolumn{3}{|l|}{ Hits $\bullet$ Inland } \\
\hline Current month & $10.535(1.079)^{* * *}$ & $16.741(2.435)^{* * *}$ & Current month & $6.516(1.209)^{* * *}$ & $13.580(2.853)^{* * *}$ \\
\hline 1 month lag & $0.646(0.405)$ & $0.612(0.762)$ & 1 month lag & $0.820(0.335)^{* *}$ & $1.103(0.390)^{* * *}$ \\
\hline 2 months lag & $-1.164(0.403)^{* * *}$ & $-0.381(0.185)^{* *}$ & 2 months lag & $-1.128(0.379)^{* * *}$ & $-0.196(0.200)$ \\
\hline \multicolumn{3}{|l|}{ HighRiskMiss } & \multicolumn{3}{|l|}{ CoastalMiss } \\
\hline Current month & $-0.084(0.510)$ & $-0.837(1.495)$ & Current month & $-0.640(0.329)^{*}$ & $3.164(1.400)^{* *}$ \\
\hline 1 month lag & $1.212(0.298)^{* * *}$ & $2.151(1.076)^{* *}$ & 1 month lag & $1.364(0.494)^{* * *}$ & $1.002(1.188)$ \\
\hline 2 months lag & $-1.997(0.360)^{* * *}$ & $-0.103(0.394)$ & 2 months lag & $0.108(0.366)$ & $0.045(0.309)$ \\
\hline R-squared & 0.666 & 0.661 & & 0.654 & 0.662 \\
\hline \multicolumn{6}{|c|}{$\begin{array}{l}\text { Notes: Results presented come from four separate linear regressions of hurricane GSI on DMA-specific TC characteristics } \\
\text { with DMA and year-month fixed effects. Models (a) and (c) use the full sample of panel data for conterminous US DMAs } \\
\text { and tropical cyclone (TC) hits 2006-2012, } N=11,705 \text {. Models (b) and (d) only consider major TCs (Category } 3 \text { and } \\
\text { stronger) as hits; a Category } 2 \text { and weaker TC does not count as a hit. A • indicates an interaction term. The designation of } \\
\text { independent variables as current month, } 1 \text { month lag, and } 2 \text { months lag correspond to the month of the search (either in the } \\
\text { month concurrent with the TC, one month following, or two months following, respectively). Huber-White robust standard } \\
\text { errors are shown in parentheses and are clustered at the DMA level. *, **, and *** indicate significance at the } 10 \%, 5 \% \text {, } \\
\text { and } 1 \% \text { level, respectively. }\end{array}$} \\
\hline
\end{tabular}




\section{Table 4}

The effect of Tropical Cyclones on climate change + global warming Internet search interest

\begin{tabular}{|c|c|c|c|c|c|}
\hline \multirow[b]{3}{*}{ Hits $\bullet$ HighRisk } & (a) & (b) & \multirow[b]{3}{*}{ Hits $\bullet$ Coastal } & \multirow{3}{*}{$\begin{array}{c}\text { (c) } \\
\text { Full model } \\
\end{array}$} & \multirow{3}{*}{$\begin{array}{c}\text { (d) } \\
\text { Major TCs only } \\
\end{array}$} \\
\hline & Full model & Major TCs only & & & \\
\hline & & & & & \\
\hline Current month & 1.354 (1.133) & $1.302(1.700)$ & Current month & $0.890(0.875)$ & $0.575(1.021)$ \\
\hline 1 month lag & $1.558(0.865)^{*}$ & 1.642 (1.962) & 1 month lag & $1.284(0.736)^{*}$ & $1.611(1.312)$ \\
\hline 2 months lag & $3.891(1.405)^{* * *}$ & 3.367 (2.083) & 2 months lag & $1.916(1.196)$ & $1.796(1.751)$ \\
\hline \multicolumn{3}{|l|}{ Hits $\bullet$ LowRisk } & \multicolumn{3}{|l|}{ Hits $\bullet$ Inland } \\
\hline Current month & $-0.616(0.739)$ & $0.006(1.026)$ & Current month & $-1.073(0.908)$ & $0.333(1.379)$ \\
\hline 1 month lag & $0.477(0.648)$ & $1.706(0.924)^{*}$ & 1 month lag & $0.474(0.813)$ & $2.082(1.072)^{*}$ \\
\hline 2 months lag & $1.442(0.778)^{*}$ & $2.010(1.213)^{*}$ & 2 months lag & $2.455(0.961)^{* *}$ & $3.318(1.127)^{* * *}$ \\
\hline \multicolumn{3}{|l|}{ HighRiskMiss } & \multicolumn{3}{|l|}{ CoastalMiss } \\
\hline Current month & $1.912(0.988)^{*}$ & $0.809(1.372)$ & Current month & $-0.128(0.934)$ & $2.280(1.344)^{*}$ \\
\hline 1 month lag & $0.495(0.954)$ & $-0.432(2.079)$ & 1 month lag & $-0.127(0.792)$ & 0.958 (1.674) \\
\hline 2 months lag & $1.420(1.232)$ & $0.482(1.700)$ & 2 months lag & $0.561(1.010)$ & $3.655(1.608)^{* *}$ \\
\hline R-squared & 0.686 & 0.685 & & 0.654 & 0.685 \\
\hline \multicolumn{6}{|c|}{$\begin{array}{l}\text { Notes: Results presented come from four separate linear regressions of climate change + global warming GSI on } \\
\text { DMA-specific TC characteristics with DMA and year-month fixed effects. Models (a) and (c) use the full sample of } \\
\text { panel data for conterminous US DMAs and tropical cyclone (TC) hits 2006-2012, N=10,372. Models (b) and (d) } \\
\text { only consider major TCs (Category } 3 \text { and stronger) as hits; a Category } 2 \text { and weaker TC does not count as a hit. A • } \\
\text { indicates an interaction term. The designation of independent variables as current month, } 1 \text { month lag, and } 2 \text { months } \\
\text { lag correspond to the month of the search (either in the month concurrent with the TC, one month following, or two } \\
\text { months following, respectively). Huber-White robust standard errors are shown in parentheses and are clustered at } \\
\text { the DMA level. *, **, and *** indicate significance at the } 10 \%, 5 \% \text {, and } 1 \% \text { level, respectively. }\end{array}$} \\
\hline
\end{tabular}




\section{Table 5}

The effect of Tropical Cyclones on climate change + global warming internet search interest as a function of distance

\begin{tabular}{lll}
\hline & \multicolumn{1}{c}{ Full model } & \multicolumn{1}{c}{ Major TCs only } \\
\cline { 2 - 3 } Distance & \multicolumn{1}{c}{} \\
Current month & $0.772(0.715)$ & $-0.508(1.174)$ \\
1 month lag & $-2.122(0.834)^{* *}$ & $-2.165(1.199)^{*}$ \\
2 months lag & $-3.288(0.993)^{* * *}$ & $-3.757(1.463)^{* *}$ \\
Distance-squared & & \\
Current month & $0.032(0.230)$ & $-0.152(0.479)$ \\
1 month lag & $0.449(0.264)^{*}$ & $0.222(0.509)$ \\
2 months lag & $0.717(0.340)^{* *}$ & $1.099(0.625)^{*}$ \\
R-squared & & 0.686 \\
\hline
\end{tabular}

Notes: Results presented come from two separate linear regressions of climate change + global warming GSI on a quadratic in distance in thousands of miles with DMA and yearmonth fixed effects. Distance is defined by the shortest distance from the centroid of a DMA to the wind-radius buffered path of a TC. Both models use the full sample of panel data for conterminous US DMAs and TC hits 2006-2012, $N=10,372$. The designation of independent variables as current month, 1 month lag, and 2 months lag correspond to the month of the search (either in the month concurrent with the TC, one month following, or two months following, respectively). Huber-White robust standard errors are shown in parentheses and are clustered at the DMA level. *, **, and *** indicate significance at the $10 \%, 5 \%$, and $1 \%$ level, respectively. 


\section{Table 6}

Six placebo tests for the effect of future Tropical Cyclones on climate change + global warming Internet search interest

\begin{tabular}{lcc}
\hline & Full model & Major TCs only \\
\hline Hits•HighRisk & (a) & (d) \\
Hits•LowRisk & $-1.549(1.157)$ & $0.511(1.778)$ \\
HighRiskMiss & $-0.278(0.738)$ & $0.202(1.076)$ \\
& $0.826(1.197)$ & $-1.149(2.134)$ \\
Hits•Coastal & $(\mathrm{b})$ & $(\mathrm{e})$ \\
Hits•Inland & $-0.351(1.041)$ & $0.501(1.214)$ \\
CoastalMiss & $-1.142(0.836)$ & $0.517(1.389)$ \\
\hline & $0.0204(1.002)$ & $1.55(1.957)$ \\
Distance & $(\mathrm{c})$ & $(\mathrm{f})$ \\
Distance-squared & $0.914(0.855)$ & $0.289(1.081)$ \\
\hline
\end{tabular}

Notes: Each panel (a-f) presents results from a separate regression of climate change + global warming GSI on DMA-specific TC characteristics listed in each panel, as well as designated market area (DMA) and year-month fixed effects. The placebo design comes from regressing GSI in time $t$ on TC characteristics in time $t+1$. Panels test for effects by heterogeneity in underlying risk (panels a and d), DMA location (panels b and e), and distance to TC track (panels c and f). Panels a, b, and c use the full sample of panel data for conterminous US DMAs and tropical cyclone (TC) hits 2006-2012, N=10,300. Models d, e, and f only consider major TCs (Category 3 and stronger) as hits. A $\bullet$ indicates an interaction term. Huber-White robust standard errors are shown in parentheses and are clustered at the DMA level. *, ${ }^{* *}$, and ${ }^{* * *}$ indicate significance at the $10 \%, 5 \%$, and $1 \%$ level, respectively. 